\title{
Explicit representation of subgrid variability in cloud microphysics yields weaker aerosol indirect effect in the ECHAM5-HAM2 climate model
}

\author{
J. Tonttila ${ }^{1,3}$, H. Järvinen ${ }^{3}$, and P. Räisänen ${ }^{2}$ \\ ${ }^{1}$ Finnish Meteorological Institute, Atmospheric Research Centre of Eastern Finland, P.O. Box 1627, 70211 Kuopio, Finland \\ ${ }^{2}$ Finnish Meteorological Institute, P.O. Box 503, 00101 Helsinki, Finland \\ ${ }^{3}$ Department of Physics, University of Helsinki, P.O. Box 64, 00014 Helsinki, Finland
}

Correspondence to: J. Tonttila (juha.tonttila@fmi.fi)

Received: 13 May 2014 - Published in Atmos. Chem. Phys. Discuss.: 12 June 2014

Revised: 9 December 2014 - Accepted: 12 December 2014 - Published: 19 January 2015

\begin{abstract}
The impacts of representing cloud microphysical processes in a stochastic subcolumn framework are investigated, with emphasis on estimating the aerosol indirect effect. It is shown that subgrid treatment of cloud activation and autoconversion of cloud water to rain reduce the impact of anthropogenic aerosols on cloud properties and thus reduce the global mean aerosol indirect effect by $19 \%$, from -1.59 to $-1.28 \mathrm{~W} \mathrm{~m}^{-2}$. This difference is partly related to differences in the model basic state; in particular, the liquid water path (LWP) is smaller and the shortwave cloud radiative forcing weaker when autoconversion is computed separately for each subcolumn. However, when the model is retuned so that the differences in the basic state LWP and radiation balance are largely eliminated, the global-mean aerosol indirect effect is still $14 \%$ smaller (i.e. $-1.37 \mathrm{~W} \mathrm{~m}^{-2}$ ) than for the model version without subgrid treatment of cloud activation and autoconversion. The results show the importance of considering subgrid variability in the treatment of autoconversion. Representation of several processes in a self-consistent subgrid framework is emphasized. This paper provides evidence that omitting subgrid variability in cloud microphysics contributes to the apparently chronic overestimation of the aerosol indirect effect by climate models, as compared to satellite-based estimates.
\end{abstract}

\section{Introduction}

Aerosol-cloud interactions and their changes due to anthropogenic aerosol emissions represent a major uncertainty in climate projections. In the Fifth Assessment Report (AR5) of the Intergovernmental Panel on Climate Change (IPCC), the uncertainty range for the effective radiative forcing due to aerosol-cloud interactions is given as -1.2 to $0.0 \mathrm{~W} \mathrm{~m}^{-2}$, with the best estimate at $-0.45 \mathrm{~W} \mathrm{~m}^{-2}$, based on expert judgment supported by satellite studies (Boucher et al., 2013). The high uncertainty in this estimate stems to a large extent from the difficulty in separating the effects of aerosolcloud interactions from other contributing feedbacks and processes. In addition, comparisons between general circulation models (GCMs) and satellite studies have indicated that models typically overestimate the sensitivity of clouds to aerosol perturbations (Quaas et al., 2009), especially in terms of precipitation susceptibility and thus the anthropogenic increase in liquid water path (LWP) (Wang et al., 2012). The median forcing value for estimates based on GCMs in AR5 $\left(-1.4 \mathrm{~W} \mathrm{~m}^{-2}\right)$ is indeed much larger in magnitude than the best estimate. The reasons for this overestimation are not fully understood.

The key topics in the model-based estimates of the aerosol indirect effects are those related to the parameterization of cloud microphysical processes, such as cloud activation of aerosols and the formation of drizzle and rain.

In many GCMs, the representation of aerosol-cloud interactions and cloud droplet activation in particular has relied on the use of parameterized effective vertical velocity in or- 
der to estimate the maximum supersaturation in a cloud layer for cloud droplet activation (e.g. Lohmann et al., 1999). This approach aims to provide a single, suitable vertical velocity value for the climate model grid cell, which is reminiscent of the typical small-scale variability of the turbulent vertical motions and is the method used in the ECHAM model. Another popular approach is to use a probability density function (PDF) to describe the subgrid variation of vertical velocity, where the grid-mean number of activated droplets is obtained by integration over the PDF (Chuang et al., 1997; Ghan et al., 1997; Storelvmo et al., 2006; Golaz et al., 2011). Tonttila et al. (2013) developed a more elaborate approach, using a PDF in the footsteps of Ghan et al. (1997) to extend the stochastic subcolumn framework of Räisänen et al. (2004). Instead of integrating over the PDF for a grid-mean cloud droplet number concentration (CDNC), random vertical velocity samples were drawn from the PDF. This enabled the calculation of CDNC individually in each cloudy subcolumn, yielding an explicit representation of the variability of cloud structure and the distribution of the microphysical properties inside the climate model grid cells. The cloudy subcolumns can be directly used in the radiation calculations by the use of the Monte Carlo Independent Column Approximation method (MCICA; Pincus et al., 2003). This is a significant advantage, as now the entire chain of processes from formation of cloud droplets to radiative transfer can be considered consistently using the same subgrid framework. In addition, it provides an innovative approach for estimating the aerosol indirect effects, which is the main topic of this paper.

A series of climate model simulations using the modified model version from Tonttila et al. (2013) is presented in this study, with focus on liquid phase stratiform clouds. These simulations demonstrate directly that omitting subgrid variability in cloud microphysics contributes to the overestimation of model-based aerosol indirect effect. A description of the model used in this study and the experimental setup is outlined in Sect. 2. Impacts of the subcolumn-based cloud microphysics on the present-day cloud properties are reported in Sect. 3. In Sect. 4, the impact of the subcolumn microphysics on the perturbation in cloud properties and radiation due to anthropogenic aerosol emissions is estimated, before drawing conclusions in Sect. 5 .

\section{Model description and experimental setup}

The experiments in this study are performed using the ECHAM5-HAM2 aerosol-climate model (the model is thoroughly described in Roeckner et al., 2003, 2006; Zhang et al., 2012). The model version considered here has been modified to include the MCICA radiation scheme (Pincus et al., 2003) and a stochastic cloud generator (Räisänen et al., 2004, 2007) with the subgrid treatment of cloud microphysical processes (Tonttila et al., 2013). The model uses the large-scale con- densation scheme of Tompkins (2002) to calculate the cloud fraction inside the GCM grid-box, and it also provides the statistical information about the subgrid variability of the total water amount needed by the stochastic cloud generator.

To summarize the operation of the stochastic subgrid framework, subgrid columns created inside the GCM gridcolumns by the stochastic cloud generator are used to describe the subgrid cloud structure and varying cloud condensate amount. First, using the PDF of total water content inside the GCM grid-box, the cloud generator defines each subcolumn as cloudy or non-cloudy at each model level. In addition, a unique value for the cloud liquid water content (LWC) is assigned in the subcolumns according to the procedure described in detail in Räisänen et al. (2004).

Second, vertical velocity is assigned to each cloudy subcolumn based on samples drawn from a Gaussian PDF $P(\mu, \sigma)$, with the mean $\mu$ taken as the GCM grid-scale vertical velocity and the standard deviation given as $\sigma=$ $1.68 \sqrt{\mathrm{TKE}}$, where TKE is the turbulent kinetic energy provided by the GCM. The coefficient 1.68 is chosen in order to match the average magnitude of the vertical velocity from the subcolumn parameterization with the effective vertical velocity according to Lohmann et al. (2007) in the default model, thus isolating the effect of explicit subgrid variability alone when comparing the results obtained using the two approaches. It is worth noting that the coefficient 1.68 is treated here as a tuning parameter for this particular comparison; physically it allocates too much energy to the turbulent vertical motion, as also discussed in Tonttila et al. (2013).

Third, the subgrid vertical velocity samples from the PDF are used to calculate cloud droplet activation, which yields the distribution of CDNC in the stochastic subcolumn space. Note that the subcolumn CDNC distribution is treated as a diagnostic property, while a prognostic formulation (Lohmann et al., 1999) is retained for the grid-scale mean CDNC. The parameterization used for cloud activation is that presented in Abdul-Razzak and Ghan (2000). Moreover, the autoconversion of cloud water into rain (Khairoutdinov and Kogan, 2000) can be treated separately for each subcolumn as well, since both LWC and CDNC are known in the subcolumn space. Since our focus is on stratiform clouds, the vertical motions to be parameterized are highly turbulent and thus presumably weakly correlated with the thermodynamical properties of the cloud (in contrast to convective cumulus clouds), as also noted in e.g. Morales and Nenes (2010). Therefore, we do not assume any correlation between vertical velocity (and thus CDNC) and LWC.

Finally, with the cloud macro- and microphysical properties defined at subgrid scale, the subcolumns are sampled by the MCICA radiation scheme for spectral integration. For radiation calculations, CDNC is constrained by an assumed minimum concentration of $40 \mathrm{~cm}^{-3}$. This constraint is present in the default model version, and is applied in the subcolumns as well in the modified model version in order to retain consistency. Removing the constraint of the minimum 
CDNC is desirable, but it would require massive adjustment of a number of physical processes in the model in order to maintain realistic representation of clouds and radiative balance, and is therefore beyond the scope of this paper.

Four model configurations are used in this study, as summarized in Table 1. All of them use subgrid columns for radiation calculations, such that each layer of the subcolumns has a cloud fraction of 0 or 1 , and cloud water content varies from one subcolumn to another (Räisänen et al., 2007). Furthermore, with the exception of the last experiment (ACACTRT), model closure parameters were not changed so that the only difference between the configurations lies in the treatment of cloud microphysics.

1. In REF, cloud droplet activation is computed using an effective vertical velocity (Lohmann et al., 2007). Consequently, subgrid-scale variations in CDNC are not considered. Furthermore, subgrid-scale cloud variability in LWC is considered in radiation calculations, but not in cloud microphysics.

2. In ACT, subgrid-scale variability of vertical velocity is considered in computing cloud activation, such that CDNC varies from one subcolumn to another. The width of the PDF for vertical velocity $(\sigma)$ was fixed such that the sample mean value corresponds to the effective vertical velocity in REF (Tonttila et al., 2013). In contrast, autoconversion is evaluated based on the gridmean values of LWC and CDNC, similarly to REF. The subgrid distributions of both LWC and CDNC are used in the radiation calculations.

3. In ACACT, vertical velocity and cloud activation are calculated in the subcolumn space, similar to ACT. Furthermore, autoconversion is now also computed in the subcolumns, considering the subgrid-scale variations in LWC and CDNC. Similar to ACT, the subgrid distributions of LWC and CDNC are used in the radiation calculations.

4. ACACTRT is similar to ACACT, but the scaling factor for autoconversion rate has been tuned down to the value 1.5 from 3.0 used in the other configurations. This model configuration will be used for estimating to which extent the indirect radiative effects of aerosols are influenced by differences in model basic states between the untuned configurations.

A 5-year simulation for the years 2001-2005 was performed with configurations 1-4, each preceded by a 3-month spinup. The simulations were nudged towards ERA-Interim reanalysis data (Dee et al., 2011) to suppress the impact of model internal variability, involving four model fields: vorticity (relaxation time scale $6 \mathrm{~h}$ ), divergence $(48 \mathrm{~h})$, atmospheric temperature $(24 \mathrm{~h})$ and logarithm of surface pressure $(24 \mathrm{~h}$ ). The model horizontal resolution was T42 (corresponding to a grid-spacing of $\approx 2.8^{\circ}$ ) with 19 layers in the
Table 1. Experimental setup indicating whether the parameterized components marked on the top row are calculated in the GCM-scale $(-)$ or in the subcolumn-space $(+)$.

\begin{tabular}{lrrr}
\hline Experiment & Radiation & Cloud activation & Autoconversion \\
\hline REF & + & - & - \\
ACT & + & + & - \\
ACACT & + & + & + \\
ACACTRT & + & + & + \\
\hline
\end{tabular}

vertical. Following Räisänen et al. (2007), we use 50 subcolumns for the McICA calculations and the subgrid cloud description. Calculating cloud microphysics in the subcolumn space adds about $25 \%$ to the computational cost of the model, compared to the REF configuration. All simulations were run twice, separately for pre-industrial (PI) and presentday (PD) conditions in terms of aerosol emissions. These were obtained using the AEROCOM emission inventories (Dentener et al., 2006) for the years 1750 and 2000, respectively. The model configurations REF and ACACT are similar to the experiments REF and SUBW presented in Tonttila et al. (2013), except that here the simulations are nudged and also include runs with pre-industrial aerosol emissions. The ACT and ACACTRT configurations presented in this paper do not have a direct counterpart in Tonttila et al. (2013).

\section{Impact of subgrid-scale parameterizations on cloud properties}

In general, the differences between REF and ACACT for present-day conditions are similar to the results presented in Tonttila et al. (2013): adding subgrid treatment of cloud activation and autoconversion typically decreases CDNC and LWC, especially over industrialized areas. Nevertheless, a brief recap of these effects is presented since the model experiments in the current paper are run in the nudged configuration and the sensitivity of cloud properties to different parameterized components is analysed.

Figure 1 shows the zonal mean present-day cloud properties for the model experiments, and corresponding global mean values are given in Table 2 . Further, observations of the total (i.e. vertically integrated) cloud fraction and cloud optical depth from the International Satellite Cloud Climatology Project (ISCCP) D1 data set (Rossow and Dueñas, 2004), averaged over the years 2001-2005 are included in Fig. 1. The corresponding simulated quantities were obtained using the ISCCP simulator (Klein and Jakob , 1999; Webb et al., 2001), which has been slightly modified in order to operate consistently with the subcolumns created by the stochastic cloud generator. The simulated total cloud fraction (Fig. 1a) is higher than observed (global mean at approximately 0.73 vs. 0.63 in the observations) especially at high latitudes and over the tropics, and similar between the different model con- 

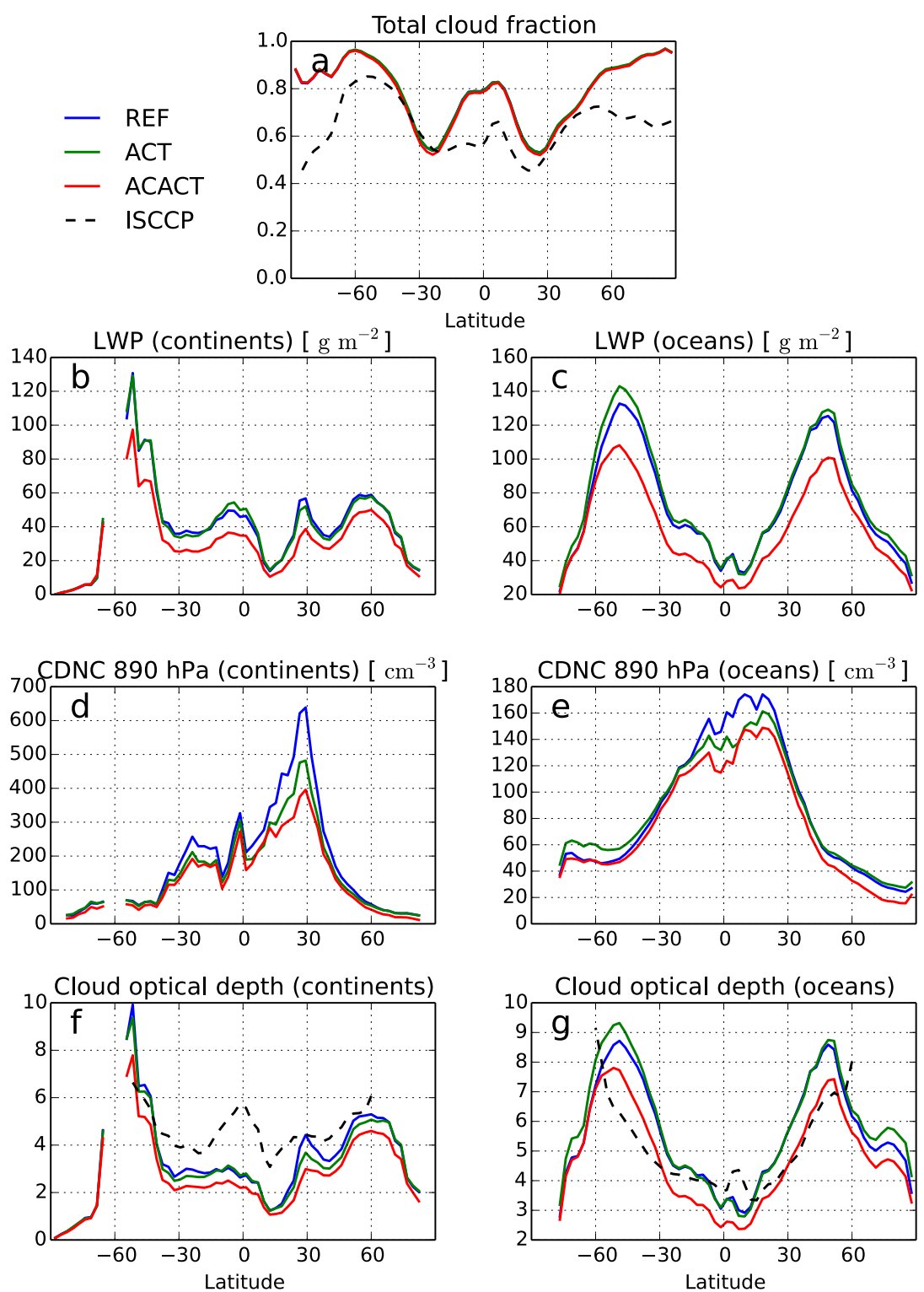

Figure 1. Zonal mean cloud properties for present-day conditions for different model configurations (summarized in Table 1) and observations from ISCCP. (a) Vertically integrated total cloud fraction, (b) liquid water path (LWP) sampled over continents, (c) LWP over oceans, (d) CDNC sampled over continents at the $890 \mathrm{hPa}$ level, (e) CDNC over oceans, (f) cloud optical depth $(\tau)$ over continents and (g) $\tau$ over oceans. Note that the ISCCP simulator was used to obtain the model estimates for (a), (f) and (g).

Table 2. Present-day global mean values in each model configuration for (from top to bottom) total cloud cover $\left(C_{\text {tot }}\right)$, liquid water path (LWP), ice water path (IWP) and CDNC burden.

\begin{tabular}{lrrrr}
\hline & REF & ACT & ACACT & ACACTRT \\
\hline$C_{\text {tot }}$ & 73.5 & 73.8 & 72.8 & 73.5 \\
LWP $\left[\mathrm{g} \mathrm{m}^{-2}\right]$ & 65.0 & 67.4 & 50.3 & 63.4 \\
IWP $\left[\mathrm{g} \mathrm{m}^{-2}\right]$ & 7.1 & 7.0 & 7.0 & 7.0 \\
CDNC burden $\left[\mathrm{cm}^{-2}\right]$ & $3.96 \times 10^{6}$ & $3.77 \times 10^{6}$ & $2.86 \times 10^{6}$ & $3.22 \times 10^{6}$ \\
\hline
\end{tabular}



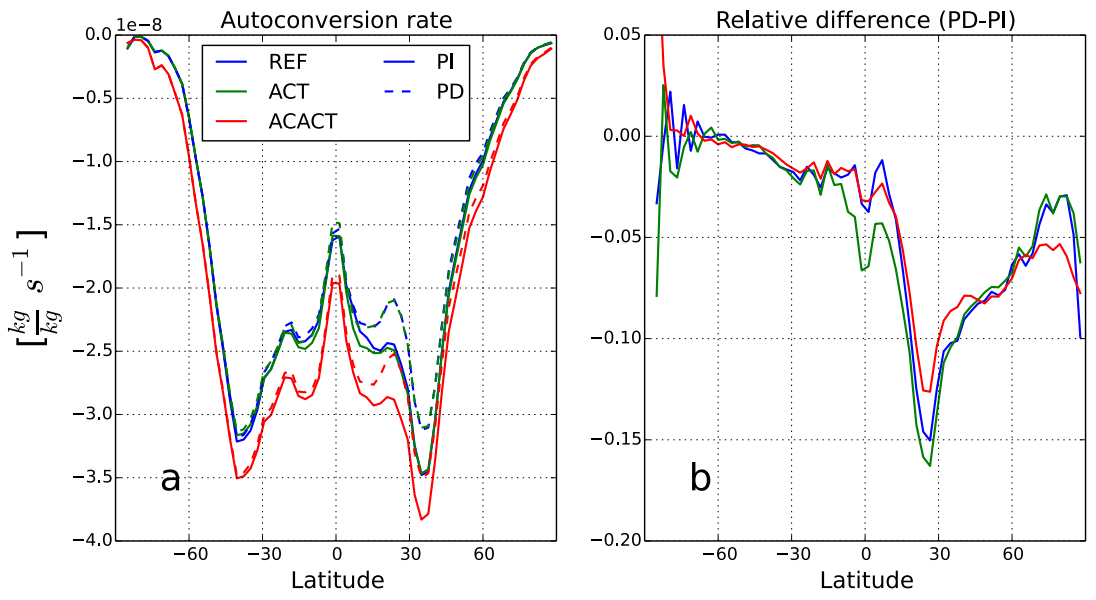

Figure 2. (a) Autoconversion rate for PI and PD conditions in $\mathrm{s}^{-1}$ at $890 \mathrm{hPa}$ and (b) the relative anthropogenic change for each model configuration.

figurations. A comparison with the ISCCP D1 data further indicates that the simulated average cloud top pressure is too low (not shown), suggesting that high clouds contribute to the overestimated total cloud fraction. Other modelling studies using ECHAM5 with the Tompkins (2002) cloud cover scheme but without the HAM2 aerosol module (e.g. Räisänen and Järvinen, 2010) show lower global-mean cloud fraction than our experiments. Therefore the overestimated total cloud cover appears to be a feature arising from the use of HAM2 together with the Tompkins (2002) cloud scheme. This issue is not influenced significantly by the inclusion of subgrid microphysics, nor is it caused by nudging (a similar feature was also present in Tonttila et al., 2013).

The LWP (Fig. 1b, c over land and oceans, respectively) is clearly smaller in ACACT than in REF and ACT. Figure 2 further shows that ACACT in general has the strongest autoconversion rate, which suggests that the smaller LWP in ACACT can be attributed to the treatment of the autoconversion process. Stronger autoconversion rate and thus lower LWP can be expected when the subgrid variability in cloud properties is taken into account. Due to the exponential dependence of the Khairoutdinov and Kogan (2000) formulation on CDNC and LWC, the autoconversion rate most often acts like a convex function. Thus, the response of the autoconversion rate to variations in CDNC and LWC about their grid-mean values is asymmetrical and tends to put more weight on higher process rates (Larson et al., 2001; Morales and Nenes, 2010; Tonttila et al., 2013), and therefore yields stronger mean autoconversion rate. Instead, in the experiment ACT the autoconversion is treated the same way as in REF, and LWP remains similar to REF in the Northern Hemisphere and over the continents, and is even slightly increased over southern mid-latitudes over the ocean. Overall, the differences in LWP between the different configurations are larger over the oceans than over continents due to larger droplet size and thus higher sensitivity to the treatment of autoconversion.

The zonal mean lower tropospheric CDNC sampled over land and oceans is shown in Fig. 1d and e, respectively. At most latitudes, the subgrid treatment of cloud activation decreases the CDNC, as indicated by the difference between ACT and REF. The largest difference occurs over land in the northern mid-latitudes, near the primary anthropogenic emission sources. In more pristine regions the differences are more modest, and over the southern oceans, the CDNC is even larger in ACT than in REF.

Tonttila et al. (2013) explained the behaviour of CDNC in terms of the modulated weighting caused by explicit subgrid variability in vertical velocity for cloud activation and its interaction with the aerosol size distribution, as the GCM gridscale average magnitude of vertical velocity is kept similar regardless of the type of parameterization in our experiments. In regions with a high concentration of cloud condensation nuclei $(\mathrm{CCN})$, most prominently at the Northern Hemisphere mid-latitudes over land, there is a strong competition for water vapour between the $\mathrm{CCN}$-sized particles. This makes the CDNC sensitive to the level of supersaturation and thus the treatment of vertical velocity. Therefore, the high frequency of occurrence of low vertical velocities in the subgrid distribution dominates in terms of CDNC, relative to the use of an effective vertical velocity, which yields a decrease in the mean CDNC. Moreover, CDNC is even further reduced in ACACT as compared to ACT, owing to the above-mentioned enhancement of the autoconversion process due to the subgrid treatment, which also influences the CDNC. Analysis of the rate of cloud droplet nucleation in Fig. 3 shows, as anticipated, that the subgrid treatment of cloud activation in ACT and ACACT decreases the nucleation rate over polluted regions compared to REF.

In contrast, in the Southern Hemisphere and over the oceans, there is much less competition for water vapour 

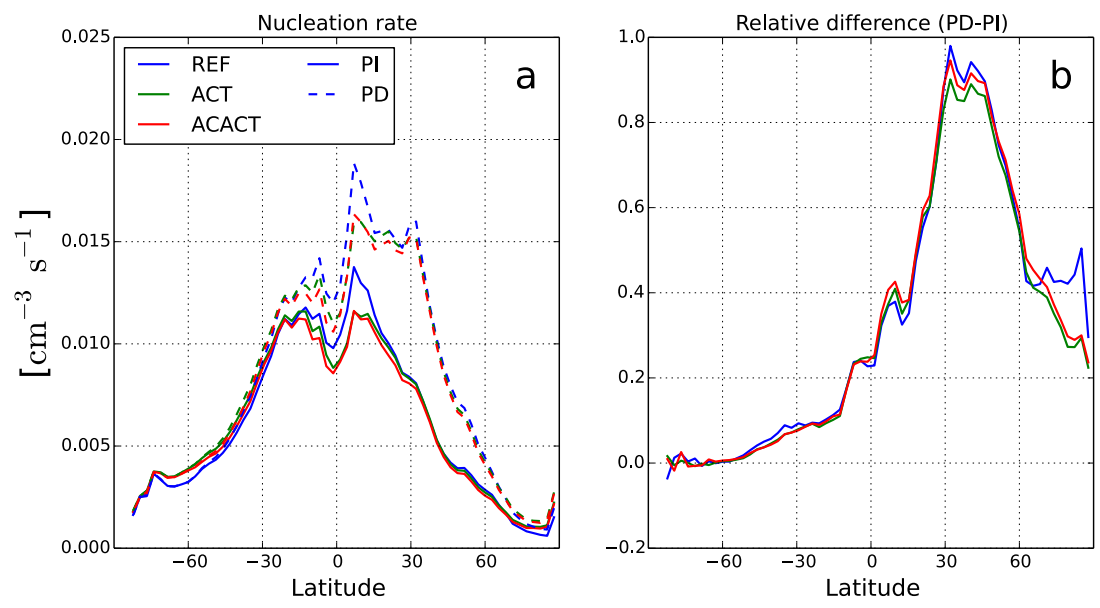

Figure 3. (a) Cloud droplet nucleation rate for PI and PD conditions in $\mathrm{cm}^{-3} \mathrm{~s}^{-1}$ at $890 \mathrm{hPa}$ and (b) the relative anthropogenic change for each model configuration.

among the relatively few $\mathrm{CCN}$ available. Thus, a sufficiently high water vapour supersaturation for the bulk of suitable aerosol particles to activate is obtained at rather low updraft speeds. This makes the CDNC relatively insensitive to variations in updraft speed at the low end of the vertical velocity spectrum. However, Fig. 3 shows that around $60^{\circ} \mathrm{S}$, the nucleation rate in both ACT and ACACT slightly exceeds that in REF. The likely explanation for this is that when the subgrid distribution of vertical velocity is accounted for, some subcolumns will get considerably higher vertical velocity than the grid-scale mean, which allows for even smaller interstitial particles (typically small Aitken mode particles in our model) to activate. However, in terms of the resulting CDNC, this is compensated in ACACT by the enhanced autoconversion due to the subgrid treatment. Thus, the CDNC around $60^{\circ} \mathrm{S}$ is similar between REF and ACACT, and slightly increased in ACT.

Contrasting the impacts seen on CDNC and LWP shows that the behaviour between the two is fairly consistent. In the Southern Hemisphere the autoconversion rate is sensitive to changes in CDNC due to the generally low CCN concentration over the oceans. Thus, the slightly increased CDNC shown by ACT is accompanied by increased LWP as compared to REF, since reduced droplet size reduces the amount of water that is converted to drizzle and rain. In comparison, in the Northern Hemisphere subtropics and mid-latitudes, CDNC is lower in ACT than in REF, especially over land, but LWP is similar to REF. This likely relates to the low sensitivity of autoconversion to small changes in CDNC in regions with high CCN concentration. Instead, for ACACT, the impact of subgrid treatment of autoconversion dominates the resulting LWP, for the most part masking out other effects.

The impact of the results above on the cloud optical properties are summarized by investigating the cloud optical depth $(\tau)$. The zonal means of $\tau$ calculated separately using data over land areas and over the oceans are shown in Fig. 1e and $\mathrm{f}$, respectively (again using the ISCCP simulator). Compared to REF, $\tau$ is clearly decreased in ACACT at all latitudes, with a larger difference over the oceans. The results from ACT are close to REF with a small increase in southern mid- and high latitudes over the oceans, and a slight decrease over Northern Hemisphere continents. The changes shown by both ACT and ACACT correspond well with the changes in LWP and CDNC discussed above. The comparison of the model results with ISCCP data shows that REF and ACT overestimate $\tau$ over the oceans and underestimate it over the continents. In ACACT, $\tau$ is underestimated over the continents as well, similar to REF and ACT. However, over the oceans, $\tau$ in ACACT agrees better with ISCCP data than in the other experiments. The most outstanding improvements also coincide with the smallest bias in total cloud fraction (i.e. in the lower mid-latitudes of each hemisphere), which makes this an encouraging result.

\section{Anthropogenic aerosol effects}

In this section, the impact of anthropogenic aerosols on cloud properties, and finally the aerosol indirect radiative effect, is evaluated as the difference between the PD and PI runs, separately for each model configuration. We first focus on the direct impacts of subgrid treatment of cloud microphysics, and consider the model versions with the same closure parameters, namely REF, ACT and ACACT. The impact of retuning the model in ACACTRT is considered toward the end of the section.

\subsection{Cloud properties}

The impact of subgrid parameterizations on the change of CDNC between PI and PD aerosol conditions at the $890 \mathrm{hPa}$ pressure level is considered in Fig. 4 and the impact on LWP change in Fig. 5. Consistent with the distribution of anthro- 

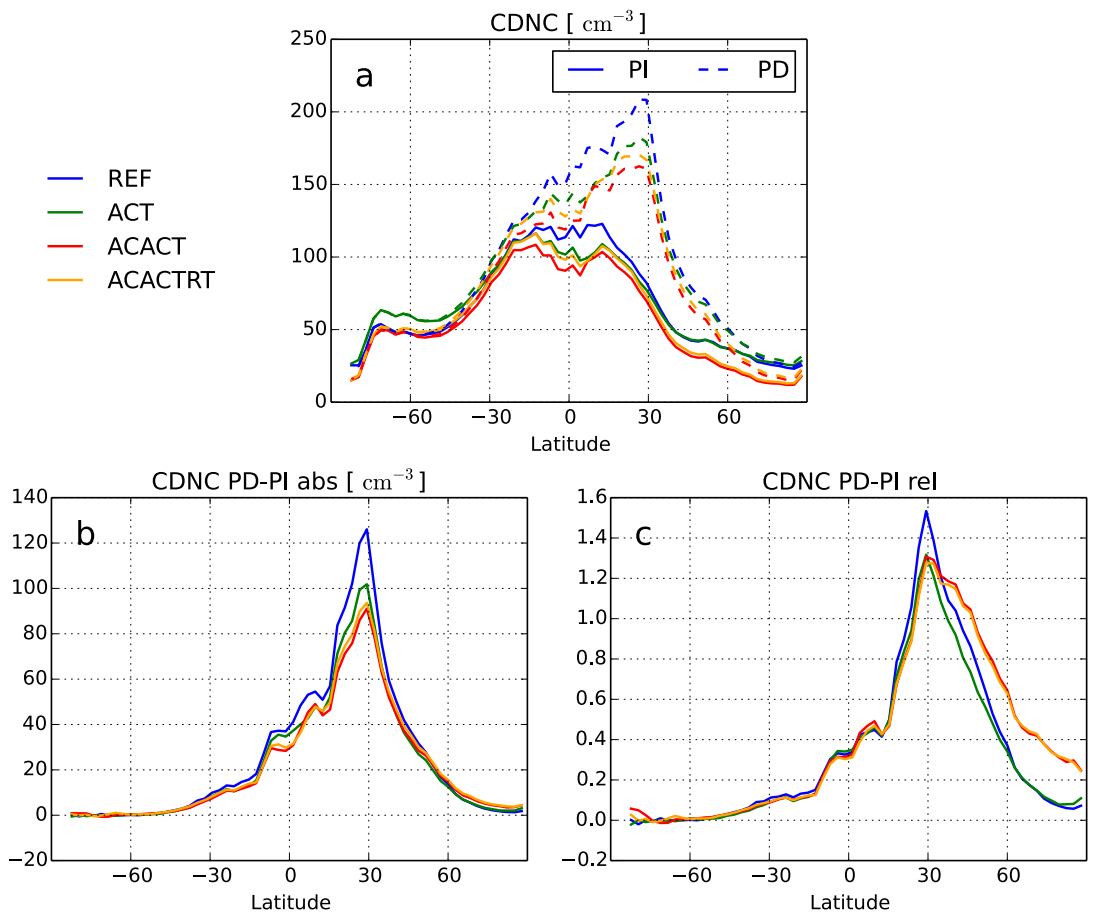

Figure 4. (a) CDNC at the $890 \mathrm{hPa}$ pressure level for PI and PD conditions in $\mathrm{cm}^{-3}$, and (b) the absolute and (c) relative anthropogenic changes in CDNC.

pogenic aerosol emissions, the changes in both the CDNC and the LWP are larger over the Northern Hemisphere than the Southern Hemisphere, in the vicinity of the main anthropogenic emission sources. It is also seen, especially in terms of the absolute differences, that the subgrid treatment of cloud microphysical parameterizations mostly reduces the sensitivity of cloud properties to the anthropogenic aerosol perturbation.

The absolute change in CDNC from PI to PD aerosol conditions is smaller in both ACT and ACACT than in REF (Fig. 4b). The global mean anthropogenic increase of CDNC is $30.5 \mathrm{~cm}^{-3}$ in ACACT, $32.1 \mathrm{~cm}^{-3}$ in ACT and $37.4 \mathrm{~cm}^{-3}$ in REF. While the differences between the different model configurations are considerable and significant at the $99 \%$ confidence level according to the two-tailed $t$ test, it should be noted that the average CDNC is smaller for ACT and ACACT than for REF in both the PI and PD simulations (Fig. 1d, e). Consequently, the inter-configuration differences in the relative $\mathrm{CDNC}$ change (i.e. $\triangle \mathrm{CDNC} / \mathrm{CDNC}$ ) between the PI and PD conditions are moderate (Fig. 4c). In terms of global-mean values, $\triangle \mathrm{CDNC} / \mathrm{CDNC}$ for $\mathrm{ACT}$ is $4 \%$ smaller than that for REF, but for ACACT it is $1 \%$ larger. These differences are not statistically significant, but some of the zonal-mean features are. First, the relative change in CDNC in the mid- and high latitudes of the Northern Hemisphere is larger for ACACT than REF at the $99 \%$ confidence level, which most likely occurs due to the suppression of the initial CDNC in the PI by the subgrid treatment of autocon- version. Second, around $30^{\circ} \mathrm{N}$, both ACT and ACACT show a smaller relative CDNC change than REF. This can be explained by the potentially increasing sensitivity of CDNC to subgrid variability of vertical velocity from low to high CCN concentrations (Tonttila et al., 2013): at high CCN concentrations, the consideration of subgrid variations in vertical velocity reduces the grid-mean CDNC more effectively than at low $\mathrm{CCN}$ concentrations, which acts to curb the increase in CDNC from PI to PD conditions.

The importance of the subgrid treatment for autoconversion is best illustrated through an examination of the anthropogenic impact on LWP (Fig. 5). Due to accounting for subgrid variability in the cloud microphysical parameterizations, the anthropogenic LWP perturbation is considerably weaker in ACACT than in REF, especially in the mid-latitudes of the Northern Hemisphere. The corresponding global mean LWP changes are $4.95 \mathrm{~g} \mathrm{~m}^{-2}$ for ACACT and $7.62 \mathrm{~g} \mathrm{~m}^{-2}$ for REF. In contrast, the global mean LWP change in ACT $\left(7.63 \mathrm{~g} \mathrm{~m}^{-2}\right)$ is almost identical to REF. Given that there is a notable difference in CDNC between the two configurations, one might expect a stronger difference in LWP as well due to the influence of CDNC on autoconversion rate. However, the PI-to-PD change of CDNC in all model configurations mainly manifests itself over the northern mid-latitudes, where CDNC is generally high. In such conditions, especially in the PD simulations, the autoconversion rate is most likely not particularly sensitive to relatively small differences in CDNC, such as those between ACT and REF. This results 
in a very small difference in the PI-to-PD change of the autoconversion rate (Fig. 2) and thus in the change of LWP as well.

As with CDNC, to better account for the LWP differences in the model basic state, the relative LWP change between PI and PD is calculated and shown in Fig. 5c for each model configuration. In the global mean, the relative PI-toPD changes are $13.3 \%$ for REF and $12.8 \%$ for ACT, respectively. Thus the difference between the two is small, and the respective zonal mean differences are also small and mostly not statistically significant. In contrast, for ACACT, the relative change in global-mean LWP is $10.9 \%$, which is approximately $18 \%$ smaller than that in REF. Globally, the difference in the relative LWP change between ACACT and REF is significant at higher than $99 \%$ level. In the zonal mean values, statistically significant differences are mainly found between 20 and $50^{\circ} \mathrm{N}$.

A deeper insight into why the LWP change between PI and PD runs is smaller in ACACT than in ACT is obtained by considering how the anthropogenic aerosol emissions alter the interaction between subgrid-scale variability of cloud properties and the cloud microphysical processes. The suggested mechanism goes as follows. First, in PD conditions, cloud activation is limited by the available CCN less frequently than in PI conditions. Therefore, the subgrid variability of vertical velocity plays a larger role in PD conditions, which results in a larger spread of the subgrid CDNC in PD conditions, both for ACT and ACACT. Second, in ACACT the autoconversion rate is calculated using subgrid values of CDNC (and LWC), while ACT uses grid-mean values. It is expected that, due to the non-linear dependence of autoconversion on CDNC, the consideration of subgrid variations in $\mathrm{CDNC}$ acts to increase the grid-mean autoconversion rate, and does so more effectively in PD conditions where the spread of CDNC is larger. This compensates for a part of the decrease in autoconversion rate that is associated with the PI-to-PD change in the grid-mean CDNC. Consequently, the reduction in the autoconversion rate from PI to PD conditions is smaller for ACACT than for ACT, as indeed shown in Fig. $2 b$ in the northern mid-latitudes. This effect is stronger at altitudes near the top of the boundary layer than near the surface, which is consistent with the expected vertical LWC distribution of stratocumulus clouds, and yields the weaker LWP change shown for ACACT.

Since subgrid variability of LWC affects autoconversion rate along with that of CDNC, PI-to-PD change in the subgrid LWC distribution can also potentially affect the LWP response in ACACT as compared to ACT. This was investigated with an additional sensitivity test (not reported in detail), in which autoconversion was computed using subgrid values of LWC but grid-mean CDNC. As expected, the results in terms of global and zonal-mean LWP fell between the ACT and ACACT experiments both for PI and PD emissions. However, the relative change of LWP between PI and PD in the sensitivity test was $12.5 \%$, which is close to the
Table 3. Pre-industrial global mean values in each model configuration for (from top to bottom) the net radiation balance, net shortwave (SW) radiation, net longwave radiation (LW), SW cloud radiative effect (SWCRE) and LW cloud radiative effect (LWCRE) in $\mathrm{W} \mathrm{m}{ }^{-2}$.

\begin{tabular}{lrrrr}
\hline & REF & ACT & ACACT & ACACTRT \\
\hline Net & 0.75 & -0.13 & 3.42 & 0.49 \\
SW & 232.22 & 231.52 & 235.23 & 231.96 \\
LW & -231.47 & -231.65 & -231.81 & -231.47 \\
SWCRE & -54.10 & -54.76 & -51.26 & -54.39 \\
LWCRE & 27.51 & 27.29 & 27.20 & 27.50 \\
\hline
\end{tabular}

corresponding change in ACT. Therefore, attribution of the smaller LWP change in ACACT primarily to the increasing spread of the subgrid CDNC and its impact on autoconversion is justified.

\subsection{Indirect radiative effect of aerosols}

The aerosol indirect radiative effect (AIE) is estimated as the perturbation in the net cloud radiative effect (CRE) at the top of the atmosphere (TOA) between the PI and PD simulations. This includes the combined effects of changing cloud lifetime, cloud extent and cloud albedo, but disregards the direct radiative effect of aerosols. The global mean radiation fluxes and cloud radiative effects for PI and PD are given in Tables 3 and 4, respectively. The global mean indirect effect for each model configuration is given in Table 5, also separately for longwave and shortwave radiation.

As expected based on the results for cloud properties, ACACT promotes weaker global mean AIE $\left(-1.28 \mathrm{~W} \mathrm{~m}^{-2}\right)$ compared to REF $\left(-1.59 \mathrm{~W} \mathrm{~m}^{-2}\right)$. Thus, the subgrid treatment of cloud microphysics reduces the net AIE by $19 \%$, with higher than $99 \%$ statistical significance. This reduction stems primarily from the perturbation in the shortwave cloud radiative effect (SWCRE), as indicated by Table 5 . The difference between ACT and REF is much weaker, only $5 \%$, and not significant. The zonal mean net AIE is shown in Fig. 6. The bulk of the difference between REF and ACACT occurs in the mid-latitudes of the Northern Hemisphere. It is also noted that the global distribution of AIE follows rather tightly the anthropogenic perturbation in LWP, which along with the difference in the global mean AIE highlights the importance of how autoconversion is calculated in the model. Nevertheless, subgrid treatment for cloud activation cannot be judged unimportant because it is essential in considering the subgrid variability in autoconversion rate.

This result is qualitatively similar to a study by Wang et al. (2011), who found that accounting for subgrid variability in cloud properties using a multi-scale modelling framework reduced the aerosol indirect effect, and that this reduction was also related to a weaker response in LWP to the an- 
Table 4. Present-day global mean values in each model configuration for (from top to bottom) the net radiation balance, net shortwave (SW) radiation, net longwave (LW) radiation, $S W$ cloud radiative effect (SWCRE) and $L W$ cloud radiative effect (LWCRE) in $\mathrm{L} \mathrm{m}^{-2}$.

\begin{tabular}{lrrrrr}
\hline & REF & ACT & ACACT & ACACTRT & CERES-EBAF \\
\hline Net & -1.36 & -2.21 & 1.62 & -1.42 & 0.79 \\
SW & 229.83 & 229.09 & 233.16 & 229.80 & 240.51 \\
LW & -231.20 & -231.30 & -231.54 & -231.22 & -239.72 \\
SWCRE & -55.92 & -56.62 & -52.81 & -56.01 & -47.26 \\
LWCRE & 27.74 & 27.63 & 27.47 & 27.76 & 26.18 \\
\hline
\end{tabular}
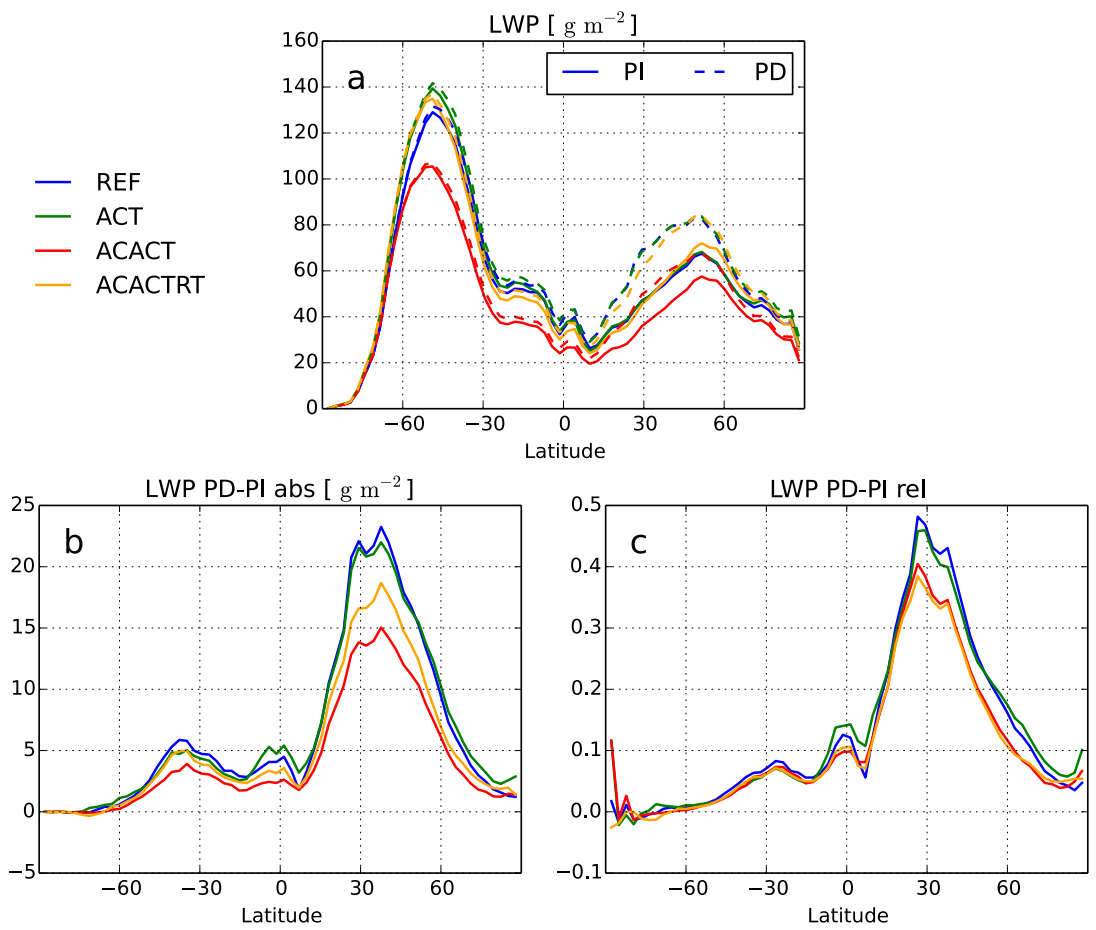

Figure 5. (a) LWP for PI and PD conditions in $\mathrm{g} \mathrm{m}^{-2}$, and (b) the absolute and (c) relative anthropogenic changes in LWP.

thropogenic aerosol increase, compared to a traditional modelling approach.

\subsection{Impacts of retuning}

A caveat regarding the results presented in Sects. 4.1 and 4.2 is that the basic state of the model, in particular the climatology of LWP and radiative fluxes, is different. In the PD simulations, the global-mean LWP for ACT is only $50.3 \mathrm{~g} \mathrm{~m}^{-2}$, as compared with $65.0 \mathrm{~g} \mathrm{~m}^{-2}$ in REF (Table 2), and the SWCRE is weaker $\left(-52.81 \mathrm{~W} \mathrm{~m}^{-2}\right.$ vs. $-55.92 \mathrm{~W} \mathrm{~m}^{-2}$; Table 4$)$. The impacts of the differing basic states of the model can be partially addressed by analysing the relative differences, but retuning of the model is necessary for robust estimation of especially the aerosol indirect radiative effect. In addition, the global-mean TOA net radiation in ACACT differs significantly from REF, by $2.67 \mathrm{~W} \mathrm{~m}^{-2}$ in the PD simulations and by $2.98 \mathrm{~W} \mathrm{~m}^{-2}$ in the PI simulations (Tables 3 and 4). If subgrid treatment of cloud microphysics were implemented in an operational setting, especially in a coupled atmosphereocean GCM, such large changes in the TOA radiation budget would need to be eliminated through model retuning.

Therefore, the PI and PD runs were repeated with a retuned version of the ACACT configuration, denoted as ACACTRT, whose results are now analysed. The primary target of tuning in this case is the TOA net radiation in the REF simulation rather than in observations. Specifically, the scaling parameter for autoconversion was reduced from the value 3.0 used in the original experiments to 1.5 in ACACTRT. This yields a substantial increase in LWP as compared with ACACT, so that the global-mean value for ACACTRT is quite close to REF in the PD simulation (Table 2), and in fact almost identical (within $0.1 \mathrm{~g} \mathrm{~m}^{-2}$ ) in the PI simulation. All global-mean radiative fluxes in Tables 3 and 4 are within $0.3 \mathrm{~W} \mathrm{~m}^{-2}$ from REF. Compared to the CERES EBAF satellite data set (Loeb et al., 2009), the global-mean TOA net flux both in REF and ACACTRT in PD conditions is more nega- 
Table 5. Global mean aerosol indirect radiative effect in each model configuration given in terms of the shortwave $\left(\mathrm{AIE}_{\mathrm{SW}}\right)$, longwave $\left(\mathrm{AIE}_{\mathrm{LW}}\right)$ and net $\left(\mathrm{AIE}_{\mathrm{Net}}\right)$ radiative forcing in $\mathrm{W} \mathrm{m}^{-2}$.

\begin{tabular}{lrrrr}
\hline & REF & ACT & ACACT & ACACTRT \\
\hline AIE $_{\text {SW }}$ & -1.82 & -1.86 & -1.55 & -1.62 \\
AIE $_{\text {LW }}$ & 0.23 & 0.35 & 0.27 & 0.25 \\
AIE $_{\text {Net }}$ & -1.59 & -1.51 & -1.28 & -1.37 \\
\hline
\end{tabular}

tive by over $2 \mathrm{~W} \mathrm{~m}^{-2}$, and the magnitude of both shortwave and (to a lesser extent) longwave CRE is overestimated (see Table 4). Presumably, the overestimated cloud cover present in all our simulations contributes to these differences.

The PI-to-PD change in CDNC at $890 \mathrm{hPa}$ in ACACTRT is very similar to ACACT in almost every respect, even though the global mean CDNC in ACACTRT is slightly larger both in the PI and PD runs (Fig. 4). In comparison, the globalmean PI-to-PD change in LWP in ACACTRT is $6.15 \mathrm{~g} \mathrm{~m}^{-2}$, which is larger than that in ACACT, but the relative change is very similar, both in terms of the meridional distribution (Fig. 5) and the global mean values (10.7\% for ACACTRT and $10.9 \%$ for ACACT). Thus, while retuning increases significantly the global-mean LWP for both the PI and PD conditions, it has little effect on the relative change between the two. The physical behaviour of cloud processes in ACACTRT therefore stays quite similar to ACACT, despite the retuning, which is understandable since the tuning parameter for autoconversion rate in ECHAM-HAM is a linear scaling coefficient. Importantly, the LWP change between PI and PD conditions in ACACTRT is substantially smaller than that in REF, by $19 \%$ both in absolute and relative terms.

Finally, as shown by Fig. 6 and Table 5, the net AIE remains significantly lower in ACACTRT than in REF, with a global mean of $-1.37 \mathrm{~W} \mathrm{~m}^{-2}$. This yields a relative difference of $-14 \%$ to REF, which is significant at the $99 \%$ level. Regionally, the differences between ACACTRT and REF are highly significant at latitudes $20-50^{\circ} \mathrm{N}$, which is expected given the distribution of the cloud property perturbations and Fig. 6. As a conclusion, the retuning yields only a limited compensation to the influence that subgrid variability in cloud microphysics exerts on the aerosol indirect effects. This result is strongly related to the similar finding on LWP. The results presented here highlight the non-linearity inherent in the processes controlling the aerosol-cloud-radiation interactions, which are now more accurately sampled since the different parameterizations from clouds to radiation are considered using the common subgrid framework (Tonttila et al., 2013).

\section{Conclusions}

In this paper, we used the ECHAM5-HAM2 climate-aerosol model augmented with a stochastic subcolumn framework

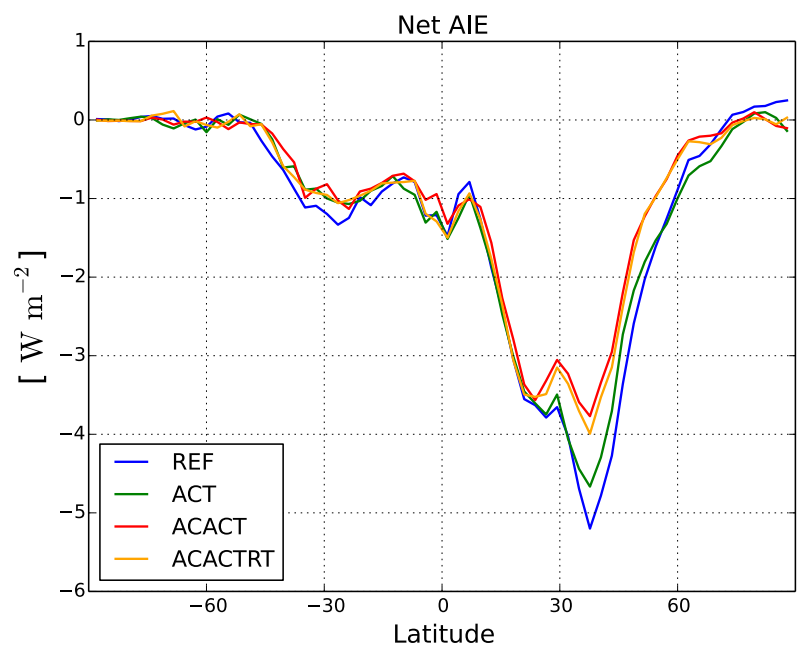

Figure 6. The net aerosol indirect effect (AIE) for each model configuration in $\mathrm{W} \mathrm{m}^{-2}$.

for cloud microphysics and radiation to study the aerosol indirect effects. Compared to a reference model configuration with GCM grid-scale cloud microphysics and thus uniform CDNC inside the GCM grid-cells, calculating cloud activation and autoconversion explicitly in the subcolumn space generally decreased the change in cloud properties between pre-industrial (PI) and present-day (PD) aerosol emission conditions. The impact of subgrid cloud microphysical parameterizations on anthropogenic CDNC change was found moderate, even though subgrid treatment for cloud activation alone already resulted in a significant decrease especially for present-day conditions. Instead, the impact on the anthropogenic LWP change was found more significant. After retuning the model to account for differences in the basic state radiation balance between the different model configurations, the use of subgrid parameterizations for both cloud activation and autoconversion decreased the PI-PD change of LWP by $19 \%$. Even though these results highlight the importance of subgrid treatment for autoconversion, it is important to note that subgrid treatment for cloud activation does significantly alter the representation of CDNC, and is a key element in order to provide a subgrid treatment for autoconversion.

The indirect radiative effect of anthropogenic aerosols was investigated by analysing the perturbation in the net cloud radiative forcing between the PI and PD conditions. Interestingly, with subgrid treatment for cloud droplet activation alone, the difference in the aerosol indirect effect to the reference simulation was relatively small and not statistically significant. While some of the similarity between the experiments is probably due to the small corresponding difference in the LWP change, it may also be, in part, related to a minimum value of CDNC $\left(40 \mathrm{~cm}^{-3}\right)$ imposed in the radiation calculations, which is applied both in the default version of the ECHAM5-HAM2 model and in the experimental version 
used in this study. It is conceivable that the impacts due to using subgrid CDNC rather than grid-mean CDNC in radiation calculations would be slightly stronger if constraints on the minimum value were to be eliminated. This could potentially impact the representation of the aerosol indirect effects as well, both in the default and experimental model configurations.

When both cloud droplet activation and autoconversion were considered in the subcolumn space, the anthropogenic perturbation in cloud radiative forcing was reduced by approximately $19 \%$ in the untuned model configuration as compared to the reference with grid-scale parameterizations. Retuning the model so that the difference in the basic state radiation budget was essentially eliminated partially compensated for this reduction, but nevertheless, the indirect effect remained $14 \%$ weaker than in the reference. Giving a single best estimate for the impact of subgrid parameterizations on the aerosol indirect effect is somewhat difficult, on one hand due to the strong modulation of the model basic state caused by the subgrid treatment and on the other hand due to the fact that the impact of subgrid parameterizations cannot be isolated if the model is retuned. It is concluded that the results above provide the range from the direct impact of subgrid cloud microphysical parameterizations (without retuning) to what more closely resembles an operational setup (with retuning).

Given that the vertical velocity for cloud activation in ECHAM5.5-HAM2 is in general quite high, reflecting the high value of $\sigma_{\mathrm{w}}$ used with the PDF of vertical velocity for the comparisons in this paper, it is possible that reducing $\sigma_{\mathrm{w}}$ to more realistic values would produce an even larger reduction in the model estimate of the indirect effect (West et al., 2014). Another aspect that possibly restricts the differences in the aerosol indirect effect between the analysed model configurations is the minimum CDNC, which is also applied in cloud microphysical calculations. This potentially has a strong effect on e.g. the autoconversion rate. It has been documented that climate models in general tend to overestimate the magnitude of the indirect radiative effects of anthropogenic aerosols (Quaas et al., 2009), especially the interaction between the amount of aerosols and the cloud liquid water path. The results of this paper provide tangible evidence that omitting subgrid variability in the model representation of cloud microphysical processes significantly contributes to this overestimation.

Acknowledgements. This work was supported by a Väisälä foundation grant from the Finnish Academy of Science and Letters and by the Academy of Finland (project numbers 127210, 283030). We would also like to thank the three anonymous reviewers who helped to improve the paper.

Edited by: J.-Y. C. Chiu

\section{References}

Abdul-Razzak, H. and Ghan, S. J.: A parameterization of aerosol activation 2: Multiple aerosol types, J. Geophys. Res., 105, 68376844, 2000.

Boucher, O., Randall, D., Artaxo, P., Bretherton, C., Feingold, G., Forster, P., Kerminen, V.-M., Kondo, Y., Liao, H., Lohmann, U., Rasch, P., Satheesh, S. K., Sherwood, S., Stevens, B., and Zhang, X. Y.: Climate Change 2013: The Physical Science Basis, Contribution of Working Group I to the Fifth Assessment Report of the Intergovernmental Panel on Climate Change, edited by: Stocker, T. F., Qin, D., Plattner, G.-K., Tignor, M., Allen, S. K., Boschung, J., Nauels, A., Xia, Y., Bex, V., and Midgley, P. M., Cambridge University Press, Cambridge, UK and New York, NY, USA, 571-658, 2013.

Chuang, C. C., Penner, J. E., Taylor, K. E., Grossman, A. S., and Walton, J. J.: An assessment of the radiative effects of anthropogenic sulfate. J. Geophys. Res., 102, 3761-3778, 1997.

Dee, D. P., Uppala, S. M., Simmons, A. J., Berrisford, P., Poli, P., Kobayashi, S., Andrae, U., Balmaseda, M. A., Balsamo, G., Bauer, P., Bechtold, P., Beljaars, A. C. M., van de Berg, L., Bidlot, J., Bormann, N., Delsol, C., Dragani, R., Fuentes, M., Geer, A. J., Haimberger, L., Healy, S. B., Hersbach, H., Hólm, E. V., Isaksen, L., Kållberg, P., Köhler, M., Matricardi, M., McNally, A. P., Monge-Sanz, B. M., Morcrette, J.-J., Park, B.K., Peubey, C., de Rosnay, P., Tavolato, C., Thépaut, J.-N., and Vitart, F.: The ERA-Interim reanalysis: configuration and performance of the data assimilation system, Q. J. Roy. Meteor. Soc., 137, 553-597, doi:10.1002/qj.828, 2011.

Dentener, F., Kinne, S., Bond, T., Boucher, O., Cofala, J., Generoso, S., Ginoux, P., Gong, S., Hoelzemann, J. J., Ito, A., Marelli, L., Penner, J. E., Putaud, J.-P., Textor, C., Schulz, M., van der Werf, G. R., and Wilson, J.: Emissions of primary aerosol and precursor gases in the years 2000 and 1750 prescribed data-sets for AeroCom, Atmos. Chem. Phys., 6, 4321-4344, doi:10.5194/acp-64321-2006, 2006.

Ghan, S. J., Leung, L. R., Easter, R. C., and Abdul-Razzak, H.: Prediction of cloud droplet number in a general circulation model, J. Geophys. Res., 102, 21777-21794, 1997.

Golaz, J.-C., Salzmann, M., Donner, L. J., Horowitz, L. W., Ming, Y., and Zhao, M.: Sensitivity of the aerosol indirect effect to subgrid variability in the cloud parameterization of the GFDL Atmosphere General Ciruclation Model AM3, J. Climate, 3145-3160, 24, doi:10.1175/2010JCLI3945.1, 2011.

Khairoutdinov, M. and Kogan, Y.: A new cloud physics parameterization in a large-eddy simulation model of marine stratocumulus, Mon. Weather Rev., 128, 229-243, 2000.

Klein, S. A. and Jakob, C.: Validation and sensitivities of frontal clouds simulated by the ECMWF model, Mon. Weather Rev., 127, 2514-2531, 1999.

Larson, V. E., Wood, R., Field, P. R., Golaz, J.-C., Haar, T. H. V., and Cotton, W. R.: Systematic biases in the microphysics and thermodynamics of numerical models that ignore subgrid-scale variability, J. Atmos. Sci., 58, 1117-1128, 2001.

Loeb, N. G., Wielicki, B. A., Doelling, D. R., Smith, G. L., Keyes, D. F., Kato, S., Manalo-Smith, N., and Wong, T.: Toward optimal closure of the Earth's top-of-atmosphere radiation budget, J. Climate, 22, 748-766, doi:10.1175/2008JCLI2637.1, 2009. 
Lohmann, U., Feichter, J., Chuang, C. C., and Penner, J. E.: Prediction of the number of cloud droplet in the ECHAM GCM, J. Geophys. Res., 104, 9169-9198, 1999.

Lohmann, U., Stier, P., Hoose, C., Ferrachat, S., Kloster, S., Roeckner, E., and Zhang, J.: Cloud microphysics and aerosol indirect effects in the global climate model ECHAM5-HAM, Atmos. Chem. Phys., 7, 3425-3446, doi:10.5194/acp-7-3425-2007, 2007.

Morales, R. and Nenes, A.: Characteristic updrafts for computing distribution-averaged cloud droplet number and stratocumulus cloud properties, J. Geophys. Res., 115, D18220, doi:10.1029/2009JD013233, 2010.

Pincus, R., Barker, H. W., and Morcrette, J.-J.: A fast, flexible, approximate technique for computing radiative transfer in inhomogeneous cloud fields, J. Geophys. Res., 108, 4376, doi:10.1029/2002JD003322, 2003.

Quaas, J., Ming, Y., Menon, S., Takemura, T., Wang, M., Penner, J. E., Gettelman, A., Lohmann, U., Bellouin, N., Boucher, O., Sayer, A. M., Thomas, G. E., McComiskey, A., Feingold, G., Hoose, C., Kristjánsson, J. E., Liu, X., Balkanski, Y., Donner, L. J., Ginoux, P. A., Stier, P., Grandey, B., Feichter, J., Sednev, I., Bauer, S. E., Koch, D., Grainger, R. G., Kirkevåg, A., Iversen, T., Seland, Ø., Easter, R., Ghan, S. J., Rasch, P. J., Morrison, H., Lamarque, J.-F., Iacono, M. J., Kinne, S., and Schulz, M.: Aerosol indirect effects - general circulation model intercomparison and evaluation with satellite data, Atmos. Chem. Phys., 9, 8697-8717, doi:10.5194/acp-9-8697-2009, 2009.

Roeckner, E., Bäuml, G., Bonaventura, L., Brokopf, R., Esch, M., Giorgetta, M., Hagemann, S., Kirchner, I., Koernblueh, L., Manzini, E., Rhodin, A., Schlese, U., Schulzweida, U., and Tompkins, A.: The atmospheric general circulation model ECHAM5, Part I: model description, Rep. 349, Max Planck Institute for Meteorology, Hamburg, Germany, 127 pp., 2003.

Roeckner, E., Brokopf, R., Esch, M., Giorgetta, M., Hagemann, S., Koernblueh, L., Manzini, E., Schlese, U., and Schulzweida, U.: Sensitivity of simulated climate to horizontal and vertical resolution in the ECHAM5 atmosphere model, J. Climate, 19, 37713791, 2006.

Rossow, W. B. and Dueñas, E. N.: The International Satellite Cloud Climatology Project (ISCCP) web site, an online resource for research, B. Am. Meteorol. Soc., 85, 167-172, 2004.

Räisänen, P. and Järvinen, H.: Impact of cloud and radiation scheme modifications on climate simulated by the ECHAM5 atmospheric GCM, Q. J. Roy. Meteor. Soc., 136, 1733-1752, doi:10.1002/qj.674, 2010.
Räisänen, P., Barker, H. W., Khairoutdinov, M. F., Li, J., and Randall, D. A.: Stochastic generation of subgrid-scale cloudy columns for large-scale models, Q. J. Roy. Meteor. Soc., 130, 2047-2067, 2004.

Räisänen, P., Järvenoja, S., Järvinen, H., Giorgetta, M., Roeckner, E., Jylhä, K., and Ruosteenoja, K.: Tests of Monte Carlo independent column approximation in the ECHAM5 atmospheric GCM, J. Climate, 20, 4995-5011, doi:10.1175/JCLI4290.1, 2007.

Storelvmo, T., Kristjánsson, J. E., Ghan, S. J., Kirkevåg, A., Seland, $\varnothing$, and Iversen, T.: Predicting cloud droplet number concentration in Community Atmosphere Model (CAM)-OSLO, J. Geophys. Res., 111, D24208, doi:10.1029/2005JD006300, 2006.

Tompkins, A. M.: A prognostic parameterization for the subgridscale variability of water vapor and clouds in large-scale models and its use to diagnose cloud cover, J. Atmos. Sci., 59, 19171942, 2002.

Tonttila, J., Räisänen, P., and Järvinen, H.: Monte Carlo-based subgrid parameterization of vertical velocity and stratiform cloud microphysics in ECHAM5.5-HAM2, Atmos. Chem. Phys., 13, 7551-7565, doi:10.5194/acp-13-7551-2013, 2013.

Wang, M., Ghan, S., Ovchinnikov, M., Liu, X., Easter, R., Kassianov, E., Qian, Y., and Morrison, H.: Aerosol indirect effects in a multi-scale aerosol-climate model PNNL-MMF, Atmos. Chem. Phys., 11, 5431-5455, doi:10.5194/acp-11-5431-2011, 2011.

Wang, M., Ghan, S., Liu, X., L'Ecuyer, T. S., Zhang, K., Morrison, H., Ovchinnikov, M., Easter, R., Marchand, R., Chand, D., Qian, Y., and Penner, J. E.: Constraining cloud lifetime effects of aerosol using A-Train satellite observations, Geophys. Res. Lett., 39, L15709. doi:10.1029/2012GL052204, 2012.

Webb, M., Senior, C., Bony, S. and Morcrette, J.-J.: Combining ERBE and ISCCP data to asses clouds in the Hadley Centre, ECMWF and LMD atmospheric climate models, Clim. Dynam., 17, 905-922, 2001.

West, R. E. L., Stier, P., Jones, A., Johnson, C. E., Mann, G. W., Bellouin, N., Partridge, D. G., and Kipling, Z.: The importance of vertical velocity variability for estimates of the indirect aerosol effects, Atmos. Chem. Phys., 14, 6369-6393, doi:10.5194/acp14-6369-2014, 2014.

Zhang, K., O’Donnell, D., Kazil, J., Stier, P., Kinne, S., Lohmann, U., Ferrachat, S., Croft, B., Quaas, J., Wan, H., Rast, S., and Feichter, J.: The global aerosol-climate model ECHAM-HAM, version 2: sensitivity to improvements in process representations, Atmos. Chem. Phys., 12, 8911-8949, doi:10.5194/acp-12-89112012, 2012. 